\title{
AS TECNOLOGIAS DE PODER NO DIAGNÓSTICO DA PANDEMIA DA COVID-19
}

\author{
Simã Catarina de Lima Pinto ${ }^{1}$ \\ Universidade Federal Fluminense - UFF \\ simacatarina@gmail.com
}

\begin{abstract}
Resumo
Este artigo retoma os conceitos de poder disciplinar e biopoder em Michel Foucault para, então, fazer um diagnóstico do contexto pandêmico causado pela Covid-19. Ao se considerar que mais da metade da população mundial foi orientada ao isolamento social, bem como à alteração de hábitos cotidianos a fim de diminuir a propagação do vírus SARS-CoV-2, é possível perceber em Foucault as medidas da técnica disciplinar e da tecnologia biopolítica, ambas direcionadas à preservação da vida da população. Considera-se que o poder disciplinar e o biopoder funcionam na atual pandemia num contexto inédito, marcado pelo avanço tecnológico.
\end{abstract}

Palavras-chave: Poder disciplinar. Biopoder. Pandemia. Avanço tecnológico.

\section{POWER TECHNOLOGIES IN THE PANDEMIC DIAGNOSIS OF COVID-19}

\begin{abstract}
This article takes up the concepts of disciplinary power and biopower in Michel Foucault to then make a diagnosis of the pandemic context caused by Covid-19. When considering that more than half of the world population was oriented towards social isolation, as well as changing daily habits in order to reduce the spread of the SARS-CoV2 virus, it is possible to perceive in Foucault the measures of disciplinary technique and biopolitical technology, both aimed at preserving the life of the population. It is considered that disciplinary power and biopower operate in the current pandemic in an unprecedented context, marked by technological progress.
\end{abstract}

Keywords: Disciplinary power. Biopower. Pandemic. Technological progress.

\footnotetext{
${ }^{1}$ Doutoranda e Mestra pelo Programa de Pós-Graduação em Sociologia e Direito na Universidade Federal
} Fluminense. Pós-graduada em Direito Público e Filosofia Contemporânea. Advogada. 


\section{INTRODUÇÃO}

A pandemia da Covid-19 não é a primeira pandemia de grande magnitude que a humanidade enfrenta, outras vieram antes, como a peste bubônica e a gripe espanhola, ambas também com características similares à atual pandemia. No entanto, a Covid-19 é marcada por um alastramento rápido, num contexto de "formas mutáveis de mobilidade física e informacional" (SHELLER; URRY, 2003, p. 9) que permite também manter as mais diversas atividades sem que seja preciso sair de casa, a despeito de grande parte da população mundial ainda não ter acesso à internet.

É com base nesse contexto que este artigo aborda os conceitos de poder disciplinar e biopoder em Michel Foucault, a partir dos quais propõe-se fazer um diagnóstico do contexto pandêmico causado pela proliferação do vírus SARS-CoV-2. Para isso, apresenta-se uma exposição sobre a analítica do poder em Foucault a fim de interpretá-la na maneira como o poder se infiltra no seio social e como ele funciona tanto celularmente, pela disciplina, quanto massivamente, pela regulamentação das populações.

A patir da análise de Foucault sobre a peste no final do século XVII, cuja leitura aqui se realiza na relação com o atual contexto, marcado pela urgência da preservação da vida, na maior parte do mundo. Não obstante este fato, no intuito de distinguir o momento dentro do qual se faz esta análise, é importante destacar que o Brasil se torna uma das únicas exceções à essa biopolítica que se dirige à manutenção da vida das populações no que se refere à adoção dos protocolos mundiais direcionados a conter o contágio da doença. Isso porque o $\mathrm{Brasil}^{2}$, embora tenha promulgado a Lei n. 13.979, de 6 de fevereiro de 2020, a "lei de quarentena", na prática, adotou o modelo de um "Estado suicidário de tipo fascista que só encontra sua força quando testa sua vontade diante do fim" (SAFATLE, 2020b. n. p.), que adota uma lógica segundo a qual o engenho não pode parar, aplicada a toda a população que passa a ser o único suprimento descartável para que o processo de acumulação e concentração permaneça sob qualquer circunstância (SAFATLE, 2020b). Isso porque desde o início da adoção das medidas de isolamento social no Brasil, o presidente eleito, “é capaz de produzir ações que desmobilizam as tentativas da sociedade em conscientizar todos da situação em que nos encontramos. Suas ações custam vidas" (SAFATLE, 2020a).

\footnotetext{
${ }^{2}$ A situação do Brasil mostra ter uma tendência maior ao aceleramento do ritmo de contágio, quando comparado aos países que tiveram altas taxas de óbitos pela Covid-19. De acordo com os dados da Fiocruz (2020), "no Brasil, entre os dias 5 e 10 de abril, os óbitos saltaram de 486 para 1.056 - em apenas 5 dias. No Equador e Estados Unidos os óbitos dobraram em 6 dias. Itália e Espanha, em 8 dias. Nas cidades de São Paulo e Rio de Janeiro, os óbitos dobraram, respectivamente, em 8 e 6 dias." Na Itália o intervalo de dias foi de 8 .
} 
Essas observações têm o objetivo de salientar que não obstante o Brasil precisar enfrentar uma grave crise política, além de uma crise sanitária, ou, como colocou Lilia Schwarcz (2020, n. p.), "uma crise profunda que é, ao mesmo tempo, política, econômica, da moral e da saúde", a análise realizada no presente artigo considera as consequências da Covid-19 num contexto global. A proliferação do SARS-CoV-2 de forma rápida e abrangente em todo o mundo fez com que em 30 de janeiro de 2020 a OMS (Organização Mundial da Saúde) declarasse a pandemia da Covid-19.

Com base nisso, no presente trabalho, os conceitos de poder disciplinar e biopoder são retomados como paradigmas no diagnóstico da atual pandemia. As semelhanças e diferenças em relação às demais pandemias e as consequências do isolamento social adotado na maior partes dos países afetados pela Covid-1933 , cuja finalidade foi evitar um número ainda maior de mortes e, consequentemente, o alastramento da doença. Isso fez com que muitos países adotassem práticas sociais disciplinares e biopolíticas direcionadas a interromper ou dimunuir a propagação do vírus e, consequentemente, da doença.

É importante colocar que o diagnóstico da pandemia que aqui se faz com base nos conceitos da analítica do poder em Foucault se propõe, antes, fazer um esboço do atual contexto histórico do que especificamente tecer críticas ao controle disciplinar e à biopolítica como tecnologias do poder que poderiam ser boas ou más em si mesmas. Isso porque a compreen são do cenário pandêmico que se impõe, mas a partir do momento que se impõe passa a ser também construído pelos indivíduos de forma celular e coletiva, refere-se a tecnologias de poder que vão se transformando no decorrer dos acontecimentos históricos e suas contingências. Suas tecituras dependem de fatores que combinam movimentos externos e internos imprevisíveis que sujeitam, mas também que dependem dos envolvidos, razão pela qual o viés analítico no presente artigo se faz mais presente do que uma possível crítica do funcionamento atual dessas tecnlogias de poder.

\section{PODER DISCIPLINAR E BIOPODER NA PANDEMIA DA COVID-19}

Em 1976, Foucault inicia uma fase de aprofundamento sobre o conceito de biopoder, embora seus estudos não tenham sido direcionados especificamente à compreensão do poder, este tema encontra-se presente em grande parte de suas obras, em A vontade de saber, Foucault inicia uma série de aulas e textos cujo tema central é retratado pelo funcionamento do poder no

\footnotetext{
${ }^{3}$ De acordo com Llorente (2020), da BBC Brasil: "estima-se que pelo menos 2,6 bilhões de pessoas foram colocadas sob alguma forma de quarentena em março. Isso representa um terço da população mundial".
} 
corpo social, o qual é caracterizado por uma "grande tecnologia de duas faces - anatômica e biológica, individualizante e especificamente voltada para os desempenhos do corpo e encarando os processos da vida - caracteriza um poder cuja função mais elevada já não é mais matar, mas investir sobre a vida, de cima a baixo" (FOUCAULT, 1985, p. 131). Ainda em 1976, em A defesa da sociedade, Foucault aponta que

parece-me que um dos fenômenos fundamentais do século XIX foi, é o que se poderia denominar a assunção da vida pelo poder: se vocês preferirem, uma tomada de poder sobre o homem enquanto ser vivo, uma espécie de estatização do biológico ou, pelo menos, uma certa inclinação que conduz ao que se poderia chamar de estatização do biológico (FOUCAULT, 1999, p. 285-286).

Em 1978, o poder permanece em seus estudos compilados em Território Segurança e População, no qual o biopoder é colocado como "o conjunto dos mecanismos pelos quais aquilo que, na espécie humana, constitui suas características biológicas fundamentais vai poder entrar numa política, numa estratégia política, numa estratégia geral de poder" (FOUCAULT, 2008, p. 3).

Esse poder que se exerce por meio de um governo da vida e sobre a vida é evidenciado num contexto no qual há uma ameaça letal concreta e constante que precisa ser enfrentada. A pandemia causada pelo vírus SARS-CoV-2 se impõe e a vida passa a ser aquilo que irá orientar o exercício do próprio poder.

Como se verifica nos países onde a Covid-19 tem gerado um grande número de mortes diariamente, a governamentalidade se exerce com a finalidade de conter a morte e manter a vida, ainda que em muitos casos tenha-se que escolher entre quem deve viver e quem deve morrer, a exemplo do que ocorreu na Itália ${ }^{4}$.

A pandemia instaura e pulveriza uma determinada formatação social que opera com base em medidas excepcionais disciplinares e biopolíticas conjuntamente a fim de conter um alto número de mortes. Ao mesmo tempo em que medidas individuais são adotadas e pulverizadas na sociedade, como procedimentos adotados pelas pessoas dentro e fora de suas residências, bem como mudanças consideráveis em seus hábitos, exercem-se também medidas em massa, prescrições que atingem toda a coletividade, uma biopolítica que alcança não algumas populações, mas a humanidade. Nesse sentido, "as disciplinas do corpo e as regulações da população constituem os dois pólos em torno dos quais se desenvolveu a organização do poder sobre a vida" (FOUCAULT, 1985, p. 131), na medida em que o biopoder não exclui a

\footnotetext{
${ }^{4}$ Conforme Wang e Lucca-Silveira (2020), na matéria da Folha de São Paulo, "Na Itália, as UTIs já não abosorvem toda demanda, e médicos precisam escolher quem receberá os cuidados e quem morrerá. Essa será a realidade no Brasil, caso o ritmo de contágio se mantenha".
} 
técnica disciplinar, mas a embute, posto serem integradas, embora os instrumentos de uma sejam totalmente diferentes (FOUCAULT, 1999), de modo que "vemos aparecer, no fim do mesmo século, algo que já não é uma anátomo-política do corpo humano, mas que eu chamaria de uma 'biopolítica' da especie humana” (FOUCAULT, 1999, p. 289). Conforme se verifica em Foucault, os regulamentos do século XVII que dispunham sobre a peste tratavam-na de uma forma estritamente disciplinar, de modo que esses regulamentos quadrilhavam

literalmente as regiões, as cidades no interior das quais existe a peste, com uma regulamentação indicando as pessoas quando podem sair, como, a que horas, o que devem fazer em casa, que tipo de alimentaçãoo devem ter, proibindo-lhes este ou aquele tipo de contato, obrigando-as a se apresentar a inspetores, a abrir a casa aos inspetores. Pode-se dizer que temos, aí, um sistema que é de tipo disciplinar (FOUCAULT, 2008, p. 14).

Já a partir do século XVIII, as práticas e mecanismos para lidar com as doenças ou, como se poderia chamar atualmente, as práticas sanitárias, deslocam-se das células individuais dos indivíduos e das casas. Foucault se utiliza do exemplo da varíola para descrever esse deslocamento celular para as massas:

\begin{abstract}
o problema fundamental vai ser o de saber quantas pessoas pegaram varíola, com que idade, com quais efeitos, qual a mortalidade, quais as lesões ou quais as sequelas, que riscos se corre fazendo-se inocular, qual a probabilidade de um indivíduo vir a morrer ou pegar varíola apesar da inoculação, quais os efeitos estatísticos sobre a populacão em geral, em suma, todo um problema que já nao é o da exclusão, como na lepra, que já não é o da quarentena, como na peste, que vai ser o problema das epidemias e das campanhas médicas por meio das quais se tentam jugular os fenômenos, tanto os epidêmicos quanto os endêmicos. (FOUCAULT, 2008, p. 14).
\end{abstract}

Desde então, as práticas se assemelham a algumas medidas adotadas a fim de conter a pandemia da Covid-19, as quais se aproximam das demais pandemias, a exemplo do que Foucault havia apontado sobre a varíola. Entretanto, a Covid-19 é marcada por um contexto no qual o mundo está conectado em redes. Os acontecimentos, os óbitos, os efeitos do isolamento, as conexões entre as pessoas são feitos interconectada e instantaneamente e antes mesmo que uma notícia se conclua ou é compreendida outra já lhe é sobreposta. As informações sobre as pesquisas relativas ao vírus são divulgadas quase instantaneamente, assim como a abertura de revistas científicas de amplo acesso a fim de combater a atual pandemia ${ }^{5}$ e a divulgação da eficácia ou não das medidas adotadas na contenção do vírus.

Diante disso, a pandemia é compreendida em níveis globais e países inteiros passam a funcionar com base não somente na disciplinarização dos corpos individuais, mas também na

\footnotetext{
${ }^{5}$ Conforme aponta Santos (2020), agências e editoras de revistas científicas passaram a promover o amplo acesso a pesquisas recentes a fim de combater o avanço da pandemia.
} 
governamentalidade de suas populações, o que faz com que a biopolítica encontre na pandemia o cenário ideal para se fazer compreender por meio de uma vivência tão próxima da realidade, conquanto os mecanismos implantados por aquela se sobressaem durante uma crise pandêmica, já que a biopolítica vai tratar de

previsões, de estimativas estatísticas, de medições globais; vai se tratar, igualmente, não de modificar tal fenômeno em especial, nao tanto tal indivíduo, na medida em que e indivíduo, mas, essencialmente, de intervir no nível daquilo que são as determinações desses fenômenos gerais, desses fenômenos no que eles tem de global (FOUCAULT, 1999, p. 293).

Tanto na disciplinarização dos corpos individuais quanto na governamentalidade de uma massa global há tecnologias de poder que se praticam contra a morte, que se espraiam por todo o corpo social. Os indivíduos se auto restringem ao mesmo tempo que são regulamentados por meio de uma série de comportamentos individuais e coletivos que se combinam a fim de conter o avanço da pandemia. Nesse aspecto, é curioso observar que, como bem apontou Farhi Neto (2020), a medida do confinamento parece ser algo fora do tempo, já que

cada época histórica desenvolveu sua própria tecnologia de combate a doenças contagiosas. Contra a lepra, a medieval exclusão. Contra a varíola, a biopolítica nascente, no final do século XVIII, inventou a vacina, que imuniza a maioria da população, mas põe em risco a vida de alguns indivíduos (FARHI NETO, 2020, p. 107).

O que se observa é que a despeito da existência e do progresso das tecnologias da informação e da comunicação, bem como de um nível científico nunca visto antes na história da humanidade, a pandemia da Covid-19 revela que a única medida até então eficaz para seu controle é, ainda, o confinamento dos indivíduos em suas casas, o que mantém a necessidade do uso da técnica disciplinar de poder utilizada em pandemias passadas para a contenção da pandemia atual. Nesse sentido, a atual pandemia, embora se assemelhe às demais em termos do uso das tecnologias de poder em Foucault, diferencia-se delas por ocorrer num momento em que a humanidade usufrui dos avanços das tecnologias da informação e da comunicação. Entretanto, a atual pandemia possui um aspecto revelador, por meio do qual se percebe que

\footnotetext{
Alguns desenvolvimentos tecnológicos são mais ou menos inócuos e criam apenas modificações triviais na forma como vivemos. Apesar disso, se ocorrem mudanças substanciais no que as pessoas fazem, se existem alterações profundas no modo de vida social, é necessário perguntar antecipadamente sobre as qualidades dos artefatos, das instituições e das experiências humanas (SANTOS, 2019, p. 135).
}

A impossibilidade de vencer a pandemia atual, seja por meio de uma vacina ou de um tratamento eficaz cuja descoberta possa livrar as pessoas da ameaça da morte e, portanto, do confinamento, faz com que as medidas do passado sejam incorporadas no presente e no futuro mais próximo, impondo às populações a fatídica espera, por meses ou até mesmo por anos, pela 
"cura" da doença ou pela imunidade contra o vírus. Com isso, é possível verificar também uma relação entre a Covid-19 e a peste declarada no final do século XVII, cujo cenário é descrito por Foucault (1987), em Vigiar e Punir, na forma como esquemas disciplinares foram suscitados pela peste a qual "recorre a separações múltiplas, a distribuições individualizantes, a uma organização aprofundada das vigilâncias e dos controles, a uma intensificação e ramificação do poder" (FOUCAULT, 1987, p. 222), de modo que os contaminados são colocados sob um "policiamento tático meticuloso onde as diferenciações individuais são os efeitos limitantes de um poder que se multiplica, se articula e se subdivide" (FOUCAULT, 1987, p. 222).

Nesse cenário, o movimento e circulação são suspensos na cidade e "a inspeção funciona constantemente. O olhar está alerta em toda parte", sob "um policiamento espacial estrito" (FOUCAULT, 1987, p. 119). De acordo com Foucault (1987, p. 222), a cidade é inteiramente atravessada "pela hierarquia, pela vigilância, pelo olhar, pela documentação" e dentro da qual funciona um poder extensivo que, além de imobilizar a cidade, age sobre os corpos individualmente (FOUCAULT, 1987). As ruas são vigiadas e cada espaço é "recortado, imóvel, fixado. Cada qual se prende a seu lugar. E, caso se mexa, corre perigo de vida, por contágio ou punição" (FOUCAULT, 1987, p. 119) e "se for absolutamente necessário sair das casas, tal se fará por turnos, e evitando-se qualquer encontro" (FOUCAULT, 1987, p. 119).

Pode se observar que a pandemia da Covid-19 se coloca como um feixe no qual todos os mecanismos da teconlogia de poder em Foucault se fazem presentes, na medida em que o controle disciplinar e a regulamentação biopolítica se combinam numa época na qual acreditava-se que a evolução tecnológica remeteria a humanidade a patamares de vida nos quais não fossem mais necessárias medidas arcaicas para a contenção de uma pandemia. Isso porque

\footnotetext{
A tecnologia biopolítica controla os fluxos, não os impede, calcula os riscos, não se importa com a vida de indivíduos concretos, mas com a vida da população (noção estatística). O confinamento celular - para cada um, uma cela, e sob exame contínuo - não é próprio à biopolítica; foi a tática disciplinar aplicada nas cidades, nos séculos XVI e XVII, contra a peste. Por isso, o confinamento atual contra a COVID-19 nos impressiona como uma tática extemporânea. Estamos num estágio biopolítico avançado, mas forçados, enquanto não há vacina, a utilizar táticas de uma época que acreditávamos revogada (FARHI NETO, 2020, p. 107-108).
}

O confinamento celular em nível global como única forma eficaz de contenção do vírus se impõe como o maior paradoxo contemporâneo: que a humanidade, em pleno Século XXI, no auge da evolução da Ciência e, portanto, da tecnologia da informação, se submeta à retomada de medidas que, embora arcaicas, são tão nescessárias à sua preservação. 


\section{OS EFEITOS DAS TECNOLOGIAS DE PODER NO CONTEXTO PANDÊMICO} ATUAL

Na distopia que se irrompe pela Covid-19, o futuro se suspende nas incertezas do tempo presente e faz lembrar Saramago: "Não sei se haverá futuro, do que agora se trata é de saber como poderemos viver neste presente, Sem futuro, o presente não serve para nada, é como se não existisse" (SARAMAGO, 1995, p. 244). Os efeitos disso abrangem e se expandem em nível global; a sensação que advém do controle e da vigilância remete a uma "utopia da cidade perfeitamente governada" (FOUCAULT, 1987, p. 222) e a constante ameaça do espraiamento da doença torna-se "a prova durante a qual se pode definir idealmente o exercício do poder disciplinar" (FOUCAULT, 1987, p. 222).

Com base nisso, há uma falsa sensação de um governo perfeito que permite o amalgamento do espaço privado no espaço público, na medida em que neste ponto ocorre a organização disciplinar dos corpos e comportamentos individuais, direcionada à proteção da coletividade. O que se faz no privado é transcendido para o público e as alterações comportamentais adotadas no espaço privado a fim de conter o avanço da pandemia, como, por exemplo, os protocolos de higienização adotados para se adentrar em casa, para o abastecimento etc. passam a ter efeitos para além do espaço privado.

Como observa Han (2020), a respeito do caso específico da China, onde a esfera privada não é algo relevante para a população, já que a vida cotidiana é observada em tempo integral por meio de câmeras de vigilância que podem ter eficiência técnica de reconhecimento facial pelas quais se torna possível observar qualquer indivíduo em espaços públicos, lojas, ruas, estações e aeroportos. Com isso, não há meios para fugir da vigilância que faz parte de toda uma infraestrutura digital a qual se mostrou extremamente eficaz para conter a epidemia (HAN, 2020). Trata-se de um conjunto de elementos de vigilância que pode ser compreendido nos mesmos termos usados por Foucault ao se referir ao que seria um tipo de "segurança". Para Foucault "o conjunto é enquadrado, de um lado, por toda urna série de vigilâncias, controles, olhares, esquadrinhamentos diversos que permitem descobrir, antes mesmo de o ladrão roubar, se ele vai roubar, etc.” (FOUCAULT, 2008, p. 07). Há que se atentar para o fato de que na Ásia esse controle de toda as esferas da vida, privada e pública, dentro do qual a divisão entre ambas se torna mitigada só é possível em razão do imperativo da coletividade, com um menor desenvolvimento cultural do individualismo acentuado (HAN, 2020).

O que permite a aceitação de certos níveis de disciplina e a internalização de condutas que em outras circunstâncias dificilmente seriam adotadas, é a regulamentação da vida por meio 
da biopolítica cujo mecanismo de funcionamento é seu entranhamento no corpo social e a partir, como aponta Foucault, de um conjunto de relações ou conjunto de procedimentos que tem como finalidade estabelecer, manter e transformar os mecanismos de poder, o que faz com que o poder não funde em si mesmo e não se dê a partir de si mesmo (FOUCAULT, 2008). Conforme coloca Foucault,

o poder é um conjunto de mecanismos e de procedimentos que têm como papel ou função e tema manter - mesmo que não o consigam - justamente o poder. É um conjunto de procedimentos, e é assim e somente assim que se poderia entender que a análise dos mecanismos de poder dá início a algo como uma teoria do poder (FOUCAULT, 2008, p. 4).

A urgência na adoção das medidas de segurança de alcance micro e macro revela os mecanismos de poder apontados por Foucault, na medida em que eles são intrínsecos em todas as relações, sendo ao mesmo tempo seu efeito e sua causa, ainda que

entre os diferentes mecanismos de poder que podemos encontrar nas relações de producão, nas relaçõees familiares, nas relações sexuais, seja possível encontrar coordenacões laterais, subordinacões hierárquicas, isomorfismos, identidades ou analogias técnicas, efeitos encadeados que permitem percorrer de uma maneira ao mesmo tempo lógica, coerente e válida o conjunto dos mecanismos de poder e apreendê-los no que podem ter de específico num momento dado, durante um período dado, num campo dado (FOUCAULT, 2008, p. 4-5).

Diante desse cenário, pode-se dizer que a pandemia revela, ainda, a mais clara expressão biopolítica que se pode ter na atualidade, uma vez que "a biopolítica lida com população, e a população como problema político, como problema a um só tempo científico e político, como problema biológico e como problema de poder" (FOUCAULT, 1999, p. 292-293), porquanto a biopolítica considera fenômenos que se tornam mais evidentes quando eclode uma pandemia, os quais se caracterizam inevitavelmente por "fenômenos coletivos, que só aparecem com seus efeitos econômicos e políticos, que só se tornam pertinentes no nível da massa" (FOUCAULT, 1999, p. 293), tornando assim, as questões individuais como de menor relevância.

Hodiernamente, o poder de morte passa a se apresentar "como complemento de um poder que se exerce, positivamente, sobre a vida, que empreende sua gestão, sua majoração, sua multiplicação, o exercício, sobre ela, de controles precisos e regulações em conjunto" (FOUCAULT, 1985, p. 129).

$\mathrm{O}$ vírus SARS-CoV-2 que deu ensejo à pandemia tornou a ameaça da morte como um meio na adoção de medidas de preservação da vida da população mundial. Trata-se de uma situação diversa daquela que permeava tanto o exercício do poder soberano quanto o funcionamento do biopoder. Se o poder soberano, em Foucault (1999) se exercia sobre a vida a partir do momento em que o soberano podia matar, o biopoder se vale da morte como 
justificativa para manter a existência biológica de uma população (FOUCAULT, 1985). Nesse aspecto, a passagem do poder soberano para o biopoder como até então se conhecia fazia com que o poder não conhecesse a morte, pois a deixaria de lado (FOUCAULT, 1999, p. 296).

A pandemia da Covid-19 se diferencia das demais pandemias enfrentas pela humanidade por se dar num contexto no qual a morte se apresenta de forma inédita, na medida em que esta, enquanto ritual privado e individual, antes da pandemia, recolhia-se no luto do seio familiar, ao passo que agora ela se torna coletiva, em constantes e sucessivos rituais fúnebres de alcance global, sem, no entanto, a presença física dos entes familiares. Nesse aspecto, o sentido coletivo da morte se impõe sobre o luto particular. A Covid-19 faz com que a morte deixe de ser "aquilo que se esconde" (FOUCAULT, 1999, p. 295) ou aquilo que seria “do que há de mais privado" (FOUCAULT, 1999, p. 296) para se tornar o oposto disso, isto é, aquilo que se revela mais intensa e ameaçadoramente pública.

Nesse sentido, o poder disciplinar e o biopoder que operam no mundo pandêmico da Covid-19 se exercem num contexto distinto e inédito, por mudanças múltiplas e instantâneas, sem que haja tempo de compreendê-las, todas atravessadas pelas tecnologias da informação e comunicação que conectam os indivíduos e os colocam diante dos acontecimentos em tempo muitas vezes real. As tragédias individuais e coletivas se conectam porque a vida individual e coletiva também se conecta, assim como as responsabilidades. A conectividade em rede permite "a crescente fluidez em termos de onde (ou quando) momentos de publicidade e privacidade ocorrem" (SHELLER; URRY, 2003, p. 4), o que faz com que se ultrapasse a delimitação entre o público e o privado de modo que questões éticas, assim como questões de vida e morte se combinem quase indistintamente. O biopoder passa a se caracterizar a partir de uma nova estrutura na qual as internações, a falta de leitos hospitalares mundo afora, as centenas de mortes diárias sejam reveladas pelos meios de comunicação instantânea e sucessivamente. As populações a vivenciam coletivamente, alterando a forma de lidar com as perdas e o próprio luto.

Percebe-se, ainda, certa indistinção na forma como o poder disciplinar e o biopoder funcionam na pandemia causada pelo vírus SARS-CoV-2, uma vez que a proteção da vida individual se funde à proteção da vida coletiva de um modo simultâneo, por não ser mais possível distinguir a proteção de uma vida das demais, uma vez que "não pode ser deixado à liberdade individual ficar ou não em casa, pois a decisão de cada um repercute imediatamente sobre os demais espalhando a pandemia e suas graves consequências" (RUIZ, 2020, n. p.). A urgência de conter a proliferação do vírus embaça a dicotomia que predomina no ocidente entre interesses individuais e coletivos, posto que a "pandemia indica que a minha atitude individual 
afeta diretamente o outro, assim como a do outro também me afeta. Em poucas ocasiões da história da humanidade se viveu uma experiência de proximidade tão radical" (RUIZ, 2020, n. p.). Assim como o comportamento de um indivíduo atinge a coletividade numa pandemia,

“o comportamento" de uma nação ou de uma região pode afetar outras. Assim, as respostas de combate a uma pandemia devem ser de escopo global. Para a ética global, o ordenamento dentro do qual a tomada de decisão ocorre deve ser global: o locus ético é o globo. Esse critério exige o reconhecimento de interesses, direitos e deveres de todos. Nenhuma nação ou região pode enfrentar sozinha uma pandemia. Somente uma resposta compartilhada, onde cada um assume uma ação necessária, será suficiente para lidar com esse problema (TONETTO, 2020, p. 125).

Nesse inédito cenário, opera-se um poder disciplinar e um biopoder, que funcionam tanto em relação às condutas individuais quanto em relação à regulamentação de condutas de toda a população mundial a fim de conter a proliferação do vírus e, consequentemente, diminuir o número de mortes a fim de preservar a vida.

\section{CONSIDERAÇÕES FINAIS}

Tendo como base os conceitos de poder disciplinar e biopoder em Michel Foucault, a pandemia da Covid-19 foi analisada no intuito de promover um diagnóstico do contexto atual. A urgência da manutenção da vida em meio a uma pandemia com alto grau de contágio e disseminação é uma ameaça constante que se sucede no tempo e altera a ordem cotidiana dos indivíduos, o que facilita a gestão da vida por meio de mecanismos técnicos e tecnológicos a fim de conter o alastramento da doença.

O diagnóstico desse cenário paradoxal, em que medidas arcaicas são retomadas a fim de conter a proliferação do vírus SARS-CoV-2, é que as ações individuais que funcionam celularmente com base no poder disciplinar têm relevância na regulamentação biopolítica das populações em nível global. Embora as tecnologias informacionais promovam a conectividade em rede, além de as pesquisas científicas permitirem um avanço tecnológico e médico progressivos, com a pandemia da Covid-19 a humanidade se vê submetida ao controle disciplinar, que remete a pandemias passadas as quais impunham aos indivíduos o confinamento por longos períodos. Trata-se de um controle disciplinar que se soma à regulamentação biopolítica. Ambas funcionam pararelamente a fim de conter o alastramento do vírus SARS-CoV-2 e faz com que o comportamento de cada indivíduo possa gerar consequências em toda a coletividade. 


\section{REFERÊNCIAS}

FARHI NETO, Leon. COVID-19 e ubupoder-19. In: REICH, Evânia; BORGES, Maria de Lourdes; XAVIER, Raquel Cipriani. Reflexões sobre uma pandemia. Néfiponline:

Florianópolis, 2020.

FIOCRUZ. Mortes por Coronavírus dobram a cada cinco dias no Brasil.

FIOCRUZ/IBICT, 22 abr. 2020. Disponível em: https://portal.fiocruz.br/noticia/mortes-porcoronavirus-dobram-cada-cinco-dias-no-brasil.

FOUCAULT, Michel. Em defesa da sociedade. Martins Fontes: São Paulo, 1999.

FOUCAULT, Michel. História da sexualidade I: a vontade de saber. Edições Graal: Rio de Janeiro, 1985.

FOUCAULT, Michel. Segurança, território, população. Martins Fontes: São Paulo, 2008.

FOUCAULT, Michel. Vigiar e Punir: nascimento da prisão. Vozes: Petrópolis, 1987. (Digital Source)

HAN, Byung-Chul. La emergencia viral y el mundo de mañana. El País, 22 mar. 2020. Disponível em: https://elpais.com/ideas/2020-03-21/la-emergencia-viral-y-el-mundo-demanana-byung-chul-han-el-filosofo-surcoreano-que-piensa-desde-berlin.html.

LLORENTE, Analía. Coronavírus: confinamento é 'o maior experimento psicológico da história', diz especialista em trauma. BBC Brasil, 2020. Disponível em: https://www.bbc.com /portuguese/geral-53204453.

RUIZ, Castor M.M. Bartolomé. Questões éticas da biopolítica na pandemia que nos assombra, Instituto Humanitas Unisinos, 24 mar. 2020. Disponível em: http://www.ihu.unis inos.br/78-noticias/597369-questoes-eticas-da-biopolitica-na-pandemia-que-nos-assombra.

SAFATLE, Vladimir. A única saída é o impeachment. El País, 20 mar. 2020a. Disponível em: https://brasil.elpais.com/opiniao/2020-03-20/a-unica-saida-e-o-impeachment.html.

SAFATLE, Vladimir. Bem vindo ao estado suicidário. N-1 Edições, 2020b. Disponível em: https://n-1edicoes.org/004.

SANTOS, Rone Eleandro. Homo digitalis: governo e construção de subjetividades em um mundo digital. Sofia, [S. l.], v. 8, n. 2, p. 128-144, jul./dez. 2019.

SANTOS, Thais Helena. Revistas científicas liberam acesso ao público para pesquisa sobre coronavírus: Publicações mais importantes da área de ciências querem contribuir com informações e divulgação de estudos para auxiliar no combate à pandemia. Jornal da USP, São Paulo, 1 abr. 2020. Disponível em: https://jornal.usp.br/universidade/revistas-cientificasliberam-acesso-ao-publico-para-pesquisa-sobre-coronavirus/.

SARAMAGO, José. Ensaio sobre a cegueira. Companhia das Letras: São Paulo, 1995.

SCHWARCZ, Lilia M. Procurar a boa utopia com alegria. In: O que fazer? Folha de São Paulo, São Paulo, 01 jun. 2020. Disponível em: https://quatrocincoum.folha.uol.com.br/br/arti gos/p/o-que-fazer. 
SHELLER, Mimi; URRY, John. Mobile Transformations of 'Public' and 'Private' Life. In: Theory Culture \& Society, v. 20, n.3, p. 107-125, 2003. Disponível em: https://www.researc hgate.net/publication/249726026_Mobile_Transformations_of_Public'_and_Private'_Life.

TONETTO, Milene Consenso. Ética global, direitos humanos e a pandemia da COVID-19. In: REICH, Evânia; BORGES, Maria de Lourdes; XAVIER, Raquel Cipriani. Reflexões sobre uma pandemia. Néfiponline: Florianópolis, 2020.

WANG, Daniel Wei Liang; LUCCA-SILVEIRA, Marcos de. Como na Itália, falta de UTI nos fará escolher entre quem vive e quem morre. Folha de São Paulo, 1 abr. 2020. Disponível em: https://www1.folha.uol.com.br/ilustrissima/2020/04/como-na-italia-falta-de-uti-nos-faraescolher-entre-quem-vive-e-quem-morre.shtml. 